\title{
Supranutritional supplementation of vitamin E influences mitochondrial proteome profile of post-mortem longissimus lumborum from feedlot heifers
}

\author{
C. Zhai ${ }^{1,2}$, S.P. Suman ${ }^{1 \#}$, M.N. Nair ${ }^{3}$, S. Li ${ }^{1}$, X. Luo ${ }^{2}$, C.M. Beach ${ }^{4}$, B.N. Harsh ${ }^{5}$, \\ D.D. Boler ${ }^{5}$, A.C. Dilger ${ }^{5}$ \& D.W. Shike \\ ${ }^{1}$ Department of Animal and Food Sciences, University of Kentucky, Lexington, KY 40546, USA \\ ${ }^{2}$ College of Food Science and Engineering, Shandong Agricultural University, Taian, Shandong, 271018, China \\ ${ }^{3}$ Department of Animal Sciences, Colorado State University, Fort Collins, CO 80523, USA \\ ${ }^{4}$ Proteomics Core Facility, University of Kentucky, Lexington, KY 40506, USA \\ ${ }^{5}$ Department of Animal Sciences, University of Illinois, Urbana, IL 61801, USA
}

(Received 25 April 2018; Accepted 7 September 2018; First published online 21 January 2019)

Copyright resides with the authors in terms of the Creative Commons Attribution 4.0 South African License.
See: http://creativecommons.org/licenses/by/4.0/za
Condition of use: The user may copy, distribute, transmit and adapt the work, but must recognize the authors and the South African
Journal of Animal Science

\begin{abstract}
Supplementation of vitamin $\mathrm{E}$ improves beef colour stability by minimizing lipid oxidation-induced myoglobin oxidation. Mitochondria affect myoglobin redox stability, and dietary vitamin $\mathrm{E}$ influences mitochondrial functionality in skeletal muscles. Nonetheless, the influence of vitamin $E$ on the mitochondrial proteome of beef skeletal muscles has yet to be investigated. Therefore, the objective of this study was to examine the effect of dietary vitamin $\mathrm{E}$ on mitochondrial proteome of post-mortem beef longissimus lumborum (LL) muscle. Beef LL muscle samples (24 hours post-mortem) were obtained from the carcasses of nine $(n=9)$ vitamin E-fed (VITE) (1000 IU vitamin $E$ for 89 days) and nine $(n=9)$ control (CONT) (diet without supplemental vitamin E) heifers. The mitochondrial proteome was analysed using two-dimensional gel electrophoresis and mass spectrometry, and nine differentially abundant spots were identified. All the differentially abundant spots were over-abundant in CONT, and the proteins were electron transport chain enzymes (NADH dehydrogenase iron-sulphur protein 8, NADH dehydrogenase flavoprotein 2, and cytochrome $c$ oxidase subunit $5 B$ ), metabolic enzymes (succinate-CoA ligase (ADP-forming) subunit beta; dihydrolipoyllysine-residue succinyltransferase component of 2-oxoglutarate dehydrogenase complex; pyruvate dehydrogenase protein $X$ component), and enzymes involved in ATP regeneration (creatine kinase S-type). The low abundance of these proteins in VITE may decrease mitochondrial activity, resulting in low oxidative activity. These findings suggest that the strong antioxidant activity of vitamin $\mathrm{E}$ leads to less expression of mitochondrial oxidative enzymes in beef skeletal muscles.
\end{abstract}

Keywords: Beef colour, lipid oxidation, mitochondrial enzymes

\#Corresponding author: spsuma2@uky.edu

\section{Introduction}

Mitochondria are the main organelles that consume oxygen and synthesize ATP, not only in living cells but also in post-mortem skeletal muscles. Intact and functionally active mitochondria can be isolated 45 days post-mortem from beef muscles (Tang et al., 2005a). Fresh meat colour is influenced by mitochondrial activity mainly through two mechanisms: oxygen consumption and metmyoglobin reducing activity. The excessive oxygen consumption by mitochondria hinders initial bloom development and red colour intensity by competing with myoglobin for available oxygen (Wittenberg \& Wittenberg, 2007). On the other hand, mitochondria generate $\mathrm{NADH}$, which is utilized for metmyoglobin reduction (through electron transportmediated and enzymatic pathways), resulting in improved fresh meat colour stability (Ramanathan et al., 2010; Mancini \& Ramanathan, 2014; Belskie et al., 2015). Thus, mitochondrial activity is one of the most important endogenous factors that influence fresh meat colour (Mancini \& Hunt, 2005; Suman \& Joseph, 2013; Suman et al., 2014; Neethling et al., 2017; Ramanathan \& Mancini, 2018). 
The cherry-red colour of retail fresh beef influences consumers' purchase decisions critically (Mancini \& Hunt, 2005; Suman et al., 2014; Neethling et al., 2017). Supplementation of vitamin E has been employed as a pre-harvest strategy to improve beef colour stability (Liu et al., 1995; Faustman et al., 1998; Sales \& Koukolova, 2011). Vitamin E is a lipid soluble antioxidant that acts as a peroxyl radical scavenger in biological systems (Traber \& Stevens, 2011). Lipid oxidation accelerates metmyoglobin formation and concomitant discolouration in fresh meats (Faustman et al., 2010), and lipid oxidation-induced discolouration is critical to fresh beef (Suman et al., 2007).

More than half of fatty acids in mitochondrial membranes are unsaturated, and thus are highly susceptible to oxidation (Lass \& Sohal, 1998; Gutierrez et al., 2002). Therefore, incorporating lipid-soluble vitamin $\mathrm{E}$ into membranes could affect mitochondrial functions. Tang et al. (2005b) reported that increasing the concentrations of alpha-tocopherol (the most biologically active form of vitamin E) kept more mitochondria intact in beef cardiac muscles and decreased mitochondrial lipid oxidation, which increased mitochondrial oxygen consumption and myoglobin redox stability, respectively.

Long-term dietary vitamin E supplementation influences gene expression and inhibits mitochondrial biogenesis in rat skeletal muscles (Strobel et al., 2011). Mitochondrial proteome comprises the enzymes and proteins that are critically involved in the organelle's biological functions. Recent studies have indicated that dietary ingredients influenced the proteome profile of post-mortem skeletal muscles (Costa-Lima et al., 2015; Wu et al., 2017). Nonetheless, the effects of dietary vitamin E on the mitochondrial proteome in post-mortem skeletal muscles are yet to be investigated. Therefore, the objective of this study was to examine the influence of dietary vitamin $\mathrm{E}$ on the mitochondrial proteome profile of post-mortem beef longissimus lumborum (LL) muscle.

\section{Materials and Methods}

The muscle samples were obtained from a feeding study (Harsh et al., 2018) completed at the University of Illinois (Urbana, IL, USA). All protocols were approved by the University of Illinois Institutional Animal Care and Use Committee (Protocol \# 15008). Eighteen Angus $\times$ Simmental heifers were used in a randomized complete block design with treatment factors including daily dietary inclusion of no supplemental (CONT) or 1,000 IU vitamin E/heifer per day (VITE). Heifers were managed as a group on a trace mineral maintenance diet prior to trial initiation and were administered an implant of $140 \mathrm{mg}$ trenbolone acetate and $14 \mathrm{mg}$ oestradiol (Component TE-H; Elanco Animal Health, Greenfield, IN). After being weighed on day 1 and 0 , heifers were stratified by bodyweight ( $n=9$ heifers per treatment). Diets were the same for the two dietary treatments with the exception of vitamin $\mathrm{E}$ inclusion as feed supplement. Diets were formulated to meet or exceed NRC (2000) recommendations and contained $20 \%$ corn silage, $35 \%$ modified wet distillers grains with solubles, $35 \%$ dry rolled corn, and $10 \%$ supplement (dry matter basis). Dietary vitamin E (dl-alpha-tocopheryl acetate) was provided to VITE heifers, and individual feed intakes of all heifers were collected with a GrowSafe feeding system (GrowSafe Systems Ltd., Airdrie, AB, Canada). Heifers were weighed at 28 day intervals and fed for ad libitum intake daily for a total of 89 days on feed. Heifers were housed in $4.88 \mathrm{~m} \times 4.88 \mathrm{~m}$ pens in a confinement barn with slatted, concrete floors covered with interlocking rubber matting. On day 90, heifers were slaughtered humanely under USDA inspection at a commercial slaughter facility. At $24 \mathrm{~h}$ post-mortem, a 2.54-cm section of LL was excised from between the 12th and 13th rib section of the carcasses, immediately vacuum-packaged, frozen at $-80^{\circ} \mathrm{C}$, and shipped in dry ice to the University of Kentucky. The results of growth performance, carcass quality, colour attributes, and lipid oxidation are discussed in Harsh et al. (2018).

Mitochondria were isolated from frozen steaks according to Lanari \& Cassens (1991), with minor modifications. Finely minced muscle tissue $(20 \mathrm{~g})$ was suspended in $40 \mathrm{~mL}$ mitochondria suspension buffer (250 mM sucrose, $10 \mathrm{mM}$ HEPES, pH 7.2). The suspension was hydrolysed using trypsin (1 mg/g of tissue) for $15 \mathrm{~min}$. After proteolytic digestion, the suspension was diluted to $200 \mathrm{~mL}$ with mitochondria isolation buffer $(67 \mathrm{mM}$ sucrose, $50 \mathrm{mM}$ Tris- $\mathrm{HCl}, 50 \mathrm{mM} \mathrm{KCl}, 10 \mathrm{mM}$ EDTA, and $0.2 \% \mathrm{BSA}, \mathrm{pH} 7.2$ ) and homogenized using a Kontes Duall grinder (Vineland, NJ, USA) followed by a Wheaton Potter-Elvehjem grinder (Millville, $\mathrm{NJ}$ ). The homogenate was centrifuged at $900 \times \mathrm{g}$ for $15 \mathrm{~min}$ with a Sorvall refrigerated RC-5C plus centrifuge (Thermo Fisher Scientific, Newtown, CT), and the supernatant was again centrifuged at $14,000 \times \mathrm{g}$ for $15 \mathrm{~min}$. The resulting mitochondrial pellets were washed twice and suspended in $0.75 \mathrm{~mL}$ mitochondria suspension buffer and divided into three aliquots. All steps were performed at $4{ }^{\circ} \mathrm{C}$.

Mitochondrial aliquots were centrifuged to pellet the mitochondria. The supernatant was discarded, and $250 \mu \mathrm{L}$ extraction buffer was added to the pellet (8.3 M urea, $2 \mathrm{M}$ thiourea, $2 \% \mathrm{CHAPS}$, and 1\% DTT). The crude mitochondrial pellet with extraction buffer was shaken vigorously for 30 min at $4{ }^{\circ} \mathrm{C}$. Samples were centrifuged at $16,000 \times g$ for $10 \mathrm{~min}$. The supernatant containing the mitochondrial proteome was used for electrophoresis. Bradford assay was used to determine the protein concentration (Bio-Rad, Hercules, CA, USA). The mitochondrial proteins $(900 \mu \mathrm{g})$ were mixed with rehydration buffer (Bio-Rad) optimized to $7 \mathrm{M}$ 
urea, $2 \mathrm{M}$ thiourea, 4\% CHAPS, $20 \mathrm{mM}$ DTT, 0.5\% Bio-Lyte 5/8 ampholyte, and 0.001\% of bromophenol blue. The mixture was loaded into immobilized pH gradient (IPG) strips ( $\mathrm{pH} 3-10,17 \mathrm{~cm}$, Bio-Rad). The IPG strips were subjected to passive rehydration for 16 hours. The first dimension isoelectric focusing (IEF) process was conducted using a Protean IEF cell system. First, an active rehydration step was conducted with low voltage $(50 \mathrm{~V})$ and increased voltage by stages, with final rapid voltage ramping to reach a total of $40 \mathrm{kVh}$. Subsequently, the IPG strips were equilibrated with equilibration buffer I (6 M urea, $0.375 \mathrm{M}$ Tris$\mathrm{HCl}, \mathrm{pH} 8.8,2 \%$ SDS, $20 \%$ glycerol, 2\% DTT) for $15 \mathrm{~min}$, followed by equilibration buffer II (6 M urea, 0.375 $\mathrm{M}$ Tris- $\mathrm{HCl}, \mathrm{pH} 8.8,2 \%$ SDS, $20 \%$ glycerol, $2.5 \%$ lodoacetamide) for $15 \mathrm{~min}$. The second dimension protein separation process was conducted by $12 \%$ sodium dodecyl sulfate polyacrylamide gel electrophoresis (SDSPAGE, 38.5:1 ratio of acrylamide to bis-acrylamide) using Protean II XL system (Bio-Rad). The gels were stained with Colloidal Coomassie Blue for 48 hours, and destained until the background of the gels was cleared. The CONT and VITE samples were evaluated under the same conditions (two gels/sample) resulting in 36 gels.

Digital images of the destained gels were captured using Versa Doc imager (Bio-Rad, Hercules, CA, USA) and were analysed with PDQuest software (Bio-Rad, Hercules, CA, USA). Images were first subjected to automatic spot detection and matching optimized with the aid of landmark protein spots. The relative volume of each spot was normalized as a percentage of the total volume of all the spots detected on the gel (Meunier et al., 2005). For each spot in a given sample, spot quantity values in duplicate gels were averaged for statistical analysis (Joseph et al., 2012). A protein spot was differentially abundant when it was associated with 1.5 -fold intensity difference and $10 \%$ significance $(P<0.10)$ level in a pairwise Student's t-test.

Protein spots that were differentially abundant between CONT and VITE were subjected to mass spectrometric identification. The protein spots were removed from the gels and then subjected to dithiothreitol reduction, iodoacetamide alkylation, and in-gel trypsin digestion. The peptides formed were extracted and concentrated. Subsequently the peptides were injected for nano-liquid chromatographyelectrospray ionization-tandem mass spectrometry (LC-ESI-MS/MS) analysis using LTQ-Orbitrap mass spectrometer (Thermo Fisher Scientific, Waltham, MA), coupled with an Eksigent Nanoflex cHiPLC ${ }^{\text {TM }}$ system (Eksigent, Dublin, CA, USA) through a nano electrospray ionization source. A reverse phase cHiPLC column $(75 \mu \mathrm{m} \times 150 \mathrm{~mm})$ was used $(300 \mathrm{~nL} / \mathrm{min}$ flow rate) to separate the peptides. Water with $0.1 \%(\mathrm{v} / \mathrm{v})$ formic acid was used for mobile phase A, and acetonitrile with $0.1 \%(\mathrm{v} / \mathrm{v})$ formic acid for mobile phase B. A $50 \mathrm{~min}$ gradient was applied. Initial 3\% mobile phase B was linearly increased to 50\% in 24 min and further to $85 \%$ and $95 \%$ for 5 min each before it was decreased to 3\%, then the column was re-equilibrated. The mass analysis method consisted of eight scan events per segment. The first scan event was an Orbitrap MS scan $(100-1600 \mathrm{~m} / \mathrm{z})$ with 60,000 resolutions for parent ions, followed by data dependent MS/MS for fragmentation of the seven most intense ions through collision induced dissociation.

The LC-MS/MS data were submitted to a local Mascot server for MS/MS protein identification through Proteome Discoverer (version 1.3, Thermo Fisher Scientific, Waltham, MA, USA) based on the Bos taurus database from National Center for Biotechnology Information (NCBI). The parameters of the MASCOT MS/MS ion search were trypsin digest with a maximum of two miscleavages, cysteine carbamidomethylation, methionine oxidation, a maximum of $10 \mathrm{ppm}$ MS error tolerance, and a maximum of $0.8 \mathrm{Da} \mathrm{MS} / \mathrm{MS}$ error tolerance. A decoy database was conducted and searched. To distribute the confidence indicators for the peptide matches, filter settings were used to determine false discovery rates (FDR). Peptide matches that passed the filter associated with the strict FDR (target setting of 0.01) were assigned as high confidence. For the MS/MS ion search, proteins with two of more high confidence peptides were considered unambiguous identifications without manual inspection, whereas proteins identified with one high confidence peptide were manually inspected and confirmed.

\section{Results and Discussion}

The image analyses of the mitochondrial proteome gels identified nine differentially abundant spots (Figure 1). The identified proteins are listed in Table 1 along with their protein name, accession number, score of the database search (ProtScore), numbers of matched peptides, and sequence coverage. All the protein spots were over-abundant in CONT. The identified proteins were involved in electron transport chain, tricarboxylic acid cycle, pyruvate metabolism, and ATP regeneration.

$\mathrm{NADH}$ dehydrogenase iron-sulphur protein 8 and NADH dehydrogenase flavoprotein 2 are part of $\mathrm{NADH}$ dehydrogenase complex (also referred to as complex I), which is located in the inner mitochondrial membrane and functions in the transfer of electrons from NADH to the respiratory chain. The role of mitochondria in meat colour has been investigated extensively, and complex I could use NADH formed from lactate (Ramanathan et al., 2010) and pyruvate (Ramanathan \& Mancini, 2010) to initiate cellular respiration. Moreover, complex I could reversibly produce NADH via reverse electron transport, and this NADH can be 
utilized for metmyoglobin reduction through enzymatic and electron transport-mediated pathways (Belskie et al., 2015). Nonetheless, the complex I is a potential site for generation of reactive oxygen species (Raha \& Robinson, 2000; Turrens, 2003; Murphy, 2009). More specifically, during forward electron transfer, only very small amounts of superoxide are produced (probably less than $0.1 \%$ of the overall electron flow (Murphy, 2009). However, during reverse electron transfer, complex I might be the most important site of superoxide production in mitochondria, with up to $5 \%$ of electrons being diverted to superoxide formation. In vitro experiments indicate that complex I can be a potent source of superoxide when succinate concentrations are high, and oxaloacetate or malate concentrations are low (Muller et al., 2008). Low abundance of NADH dehydrogenase observed in the vitamin E-fed beef may result in a low probability of generation of reactive oxygen species, which could also explain low lipid oxidation in vitamin E-supplemented beef (Faustman et al., 1989).

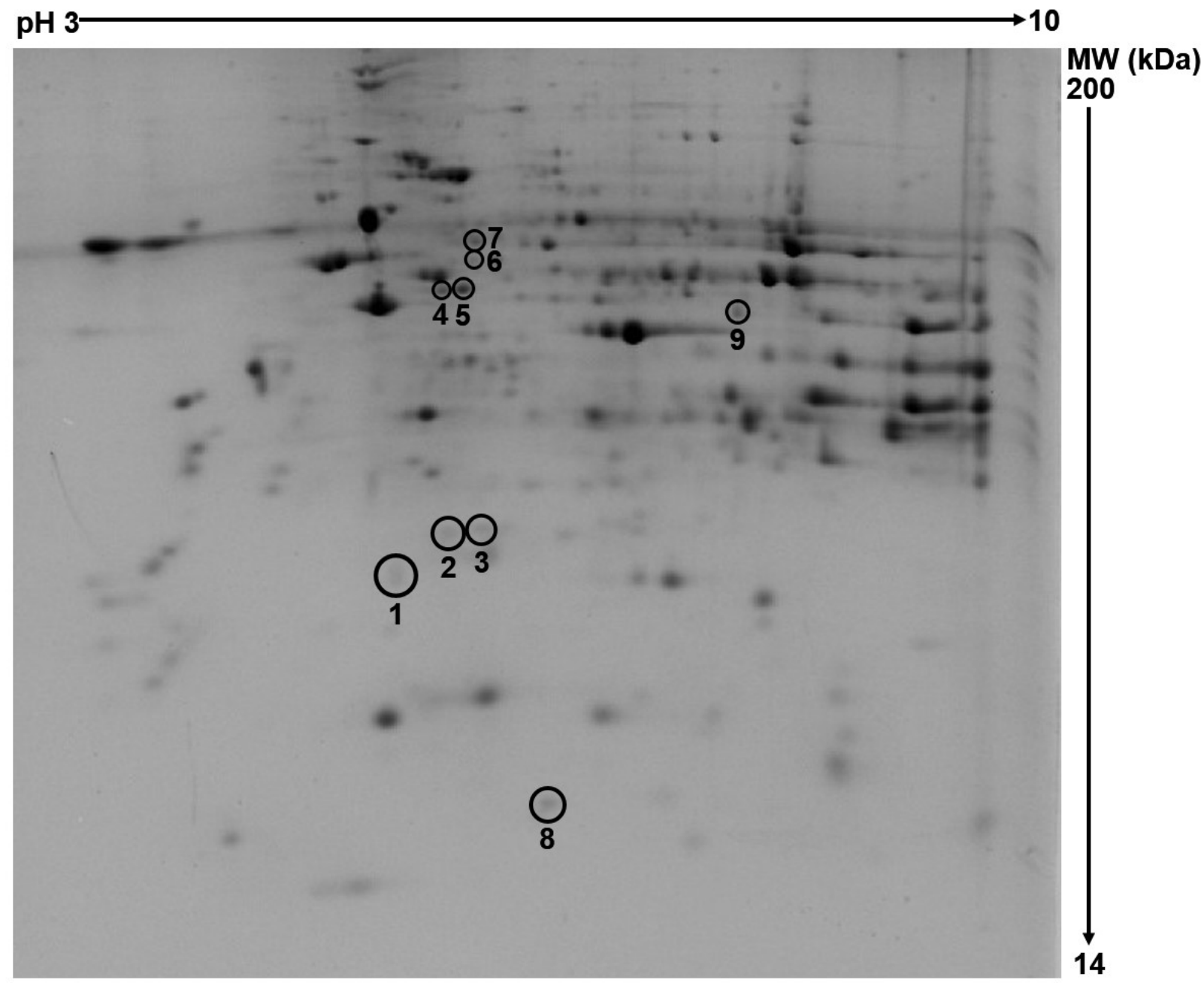

Figure 1 Coomassie-stained two-dimensional gel of mitochondrial proteome extracted from longissimus lumborum muscle of beef heifers fed on vitamin E. Nine protein spots differentially abundant in control and vitamin E-fed heifers are encircled and numbered

Cytochrome c oxidase, also referred to as complex IV, is the last enzyme in the mitochondrial respiratory electron transport chain in the mitochondrial membrane. It receives an electron from each of four cytochrome c molecules, and transfers them to one oxygen molecule, facilitating the conversion of molecular oxygen to water. Restraining cytochrome c oxidase builds an anoxic condition, by which electrons accumulate at a site between complexes III and IV and become more available for metmyoglobin reduction (Tang et al., 2005a). Wittenberg \& Wittenberg (2007) reported that oxygen can be delivered to cytochrome c oxidase in the inner membrane via facilitated diffusion, which results from increasing oxygen availability that 
occurs when oxymyoglobin is close to mitochondria. Mohan et al. (2010) reported that the differences in cytochrome c oxidase activity among the three muscles ( $L L>$ psoas major > semitendinosus) corresponded well with metmyoglobin reducing activity and colour stability differences exhibited by these muscles. Ke et al. (2017) reported approximately 1.8-fold difference in mitochondrial content between beef psoas major and LL muscles and suggested that greater oxygen consumption rate may possibly be detrimental to colour stability. The low abundance of cytochrome c oxidase in vitamin E-fed beef observed in the present study may decrease oxygen consumption rate, similar to the low oxygen consumption rates in the muscles with low levels of mitochondria.

Table 1 Identity and functional rules of differentially abundant proteins in mitochondrial proteome of longissimus lumborum muscle from beef heifers fed on vitamin $\mathrm{E}$

\begin{tabular}{|c|c|c|c|c|c|c|c|}
\hline Spot $^{a}$ & Protein & $\begin{array}{l}\text { Accession } \\
\text { No: }\end{array}$ & $\begin{array}{l}\text { ProtScorel } \\
\text { Matched } \\
\text { peptides }\end{array}$ & $\begin{array}{l}\text { Sequence } \\
\text { Coverage } \\
(\%)\end{array}$ & Function & $\begin{array}{l}\text { Over- } \\
\text { abundant } \\
\text { treatment }\end{array}$ & $\begin{array}{l}\text { Spot } \\
\text { ratio }\end{array}$ \\
\hline 1 & $\begin{array}{l}\text { NADH dehydrogenase } \\
\text { iron-sulfur protein } 8\end{array}$ & P42028 & 611.99/73 & 52.83 & $\begin{array}{l}\text { Electron transport } \\
\text { chain }\end{array}$ & CONT & $1.86^{\mathrm{C}}$ \\
\hline 2 & $\begin{array}{l}\text { NADH dehydrogenase } \\
\text { flavoprotein } 2\end{array}$ & P04394 & $441.23 / 28$ & 60.24 & $\begin{array}{l}\text { Electron transport } \\
\text { chain }\end{array}$ & CONT & $2.52^{\mathrm{c}}$ \\
\hline 3 & $\begin{array}{l}\text { NADH dehydrogenase } \\
\text { flavoprotein } 2\end{array}$ & P04394 & $1712.36 / 94$ & 70.28 & $\begin{array}{l}\text { Electron transport } \\
\text { chain }\end{array}$ & CONT & $1.72^{\mathrm{c}}$ \\
\hline 4 & $\begin{array}{l}\text { Succinate-CoA ligase } \\
\text { [ADP-forming] subunit } \\
\text { beta }\end{array}$ & Q148D5 & $3036.79 / 125$ & 72.14 & $\begin{array}{l}\text { Tricarboxylic acid } \\
\text { cycle }\end{array}$ & CONT & $1.50^{\mathrm{C}}$ \\
\hline 5 & $\begin{array}{l}\text { Succinate-CoA ligase } \\
\text { [ADP-forming] subunit } \\
\text { beta }\end{array}$ & Q148D5 & $7271.85 / 294$ & 76.24 & $\begin{array}{l}\text { Tricarboxylic acid } \\
\text { cycle }\end{array}$ & CONT & $1.50^{\circ}$ \\
\hline 6 & $\begin{array}{l}\text { Dihydrolipoyllysine- } \\
\text { residue } \\
\text { Succinyltransferase } \\
\text { component of 2- } \\
\text { oxoglutarate } \\
\text { dehydrogenase complex }\end{array}$ & P11179 & $2625.77 / 131$ & 57.14 & $\begin{array}{l}\text { Tricarboxylic acid } \\
\text { cycle }\end{array}$ & CONT & $1.83^{\mathrm{C}}$ \\
\hline 7 & $\begin{array}{l}\text { Pyruvate dehydrogenase } \\
\text { protein X component }\end{array}$ & P22439 & $3643.62 / 183$ & 55.89 & $\begin{array}{l}\text { Pyruvate } \\
\text { metabolism }\end{array}$ & CONT & $1.67^{\circ}$ \\
\hline 8 & $\begin{array}{l}\text { Cytochrome c oxidase } \\
\text { subunit } 5 B\end{array}$ & P00428 & $669.16 / 59$ & 42.64 & $\begin{array}{l}\text { Electron transport } \\
\text { chain }\end{array}$ & CONT & $1.71^{\mathrm{C}}$ \\
\hline 9 & Creatine kinase S-type & Q3ZBP1 & $2225.33 / 136$ & 72.55 & ATP regeneration & CONT & $1.69^{\mathrm{C}}$ \\
\hline
\end{tabular}

\footnotetext{
${ }^{a}$ Spot number refers to the numbered spots in gel image (Figure 1). Spots are identified by accession number (UniProt), ProtScore, matched peptides number, and sequence coverage of peptides

${ }^{b}$ CONT: non-vitamin E diet; VITE: 1000 IU vitamin E diet for 89 days

${ }^{\mathrm{c}}$ Spot ratio of CONT/VITE
}

Pyruvate dehydrogenase protein $X$ component is part of the pyruvate dehydrogenase complex, which contributes to transforming pyruvate into acetyl-CoA through pyruvate decarboxylation. Acetyl-CoA is then used in the citric acid cycle to carry out cellular respiration, and thus pyruvate dehydrogenase contributes to linking the glycolytic pathway to the citric acid cycle and releasing energy via NADH. Post-mortem bovine mitochondria can use pyruvate for oxygen consumption (Ramanathan \& Mancini, 2010). Abraham et al. (2017) observed that the intensity of pyruvic acid in colour-stable beef LL was three times more than that in colour-labile psoas major. The low abundance of pyruvate dehydrogenase in the VITE group may result in lower conversion of pyruvate into acetyl-CoA so that more pyruvate could remain in post-mortem skeletal muscles resulting in an improved beef colour stability. However, Joseph et al. (2012) reported that pyruvate dehydrogenase was more abundant in the sarcoplasmic proteome of colour-stable beef LL than in colourlabile psoas major.

Dihydrolipoyllysine-residue succinyltransferase component of the 2-oxoglutarate dehydrogenase complex was identified in spot 6 . The 2-oxoglutarate dehydrogenase complex is composed of three components. Dihydrolipoyllysine-residue succinyltransferase can reversibly transform coenzyme A and enzyme N6-(S-succinyldihydrolipoyl) lysine to enzyme N6-(dihydrolipoyl) lysine and succinyl coenzyme A. 
The reaction catalysed by 2-oxoglutarate dehydrogenase complex in the citric acid cycle generates NADH for the respiratory electron-transport chain. Increased oxoglutarate dehydrogenase levels increase the concentrations of NADH, which intensify the oxidative phosphorylation. This ATP generating pathway also gives rise to more radical species, which can cause oxidative stress to the cells (Tretter \& Adam-Vizi, 2005). Thus, it is logical that low abundance of oxoglutarate dehydrogenase component could cause low oxidative stress and improved mitochondrial integrity when beef animals are supplemented with vitamin $E$.

Succinate-CoA ligase (also known as succinyl coenzyme A synthetase or succinyl-CoA synthetase) is an enzyme in the mitochondrial matrix, which catalyses the reversible reaction of succinyl CoA to succinate. The gene for succinate-CoA ligase is transcribed along with the gene for 2-oxoglutarate dehydrogenase. Moreover, succinate-CoA ligase is the only enzyme in the citric acid cycle that catalyses a reaction in which a nucleoside triphosphate is formed by substrate-level phosphorylation. In mammals, tissue typically involved in catabolic metabolism (that is, muscle) express succinate-CoA ligase [ADP-forming] subunit beta (Lambeth et al., 2004).

Creatine kinase S-type is a mitochondrial creatine kinase isoenzyme, which reversibly catalyses the transfer of phosphate between ATP and various phosphagens (for example creatine phosphate). Creatine kinase S-type has rarely been reported in meat research. However, Joseph et al. (2012) reported that creatine kinase (M chain) was more abundant in beef LL (colour-stable muscle) compared to psoas major (colour-labile muscle). The over-abundance of creatine kinase M-type in colour-stable LL beef steaks can increase the creatine content, which can minimize myoglobin oxidation and improve colour stability (Canto et al., 2015). In beef semimembranosus muscles, Nair et al. (2016) documented that creatine kinase M-type was over-abundant in colour-stable outside semimembranosus steaks compared with the colour-labile inside semimembranosus steaks.

Dietary vitamin E supplementation enhances the lipid and colour stabilities in beef (Faustman et al., 1998) through antioxidant function. The results of the present study indicated that mitochondria from LL muscle of heifers supplemented with vitamin E demonstrated lower abundance of enzymes involved in the electron transport chain, tricarboxylic acid cycle, pyruvate metabolism, and ATP regeneration, compared with mitochondria from heifers that did not receive vitamin E supplementation (VITE). The low mitochondrial activity, as a result of lower abundance of enzymes, could decrease the oxygen consumption in post-mortem muscles ultimately resulting in an increased colour stability. Moreover, low abundance of enzymes (such as $\mathrm{NADH}$ dehydrogenase) generating reactive oxygen species could also lead to low lipid oxidation in beef from vitamin E-supplemented cattle. Overall, these findings indicated that dietary vitamin E appears to influence mitochondrial proteome of beef LL by decreasing mitochondrial activity and decreasing oxidative stress.

\section{Conclusion}

The results of the present study suggested that dietary vitamin E decreased the abundance of mitochondrial proteins involved in oxidative metabolism and ATP generation in post-mortem beef LL muscle. The strong antioxidant protection offered by vitamin $\mathrm{E}$ may have led to low expression of metabolic proteins in the VITE group, leading to low mitochondrial activity and resulting in lower oxidative stress. Further studies should examine the influence of vitamin $E$ on the mitochondrial proteome in live and perimortem muscles to understand how this antioxidant modulates oxidative stability of skeletal muscles.

\section{Acknowledgements}

This is publication number 18-07-051 of the Kentucky Agricultural Experiment Station and is published with the approval of the director. This work was supported by the National Institute of Food and Agriculture, U.S. Department of Agriculture, Hatch-Multistate Project 1014747.

\section{Authors' Contributions}

Conception and design: SPS, XL, DDB, ACD, \& DWS; data collection and analyses: CZ, BHN, MNN, SL, and CMB; drafting of paper: CZ; critical revision and final approval of version to be published: SPS.

\section{Conflict of Interest Declaration}

The authors declare that they have no affiliations with any organization or entity with any financial or non-financial interest that could bias the subject matter and outcomes discussed in this manuscript.

\section{References}

Abraham, A., Dillwith, J.W., Mafi, G.G., VanOverbeke, D.L. \& Ramanathan, R., 2017. Metabolite profile differences between beef longissimus and psoas muscles during display. Meat Mus. Bio. 1, 18-27.

Belskie, K.M., Van Buiten, C.B., Ramanathan, R. \& Mancini, R.A., 2015. Reverse electron transport effects on NADH formation and metmyoglobin reduction. Meat Sci. 105, 89-92. 
Canto, A.C., Suman, S.P., Nair, M.N., Li, S., Rentfrow, G., Beach, C.M., Silva, T.J., Wheeler, T.L., Shackelford, S.D., Grayson, A., McKeith, R.O. \& King, D.A., 2015. Differential abundance of sarcoplasmic proteome explains animal effect on beef longissimus lumborum colour stability. Meat Sci. 102, 90-98.

Costa-Lima, B.R., Suman, S.P., Li, S., Beach, C.M., Silva, T.J., Silveira, E.T., Bohrer, B.M. \& Boler, D.D., 2015. Dietary ractopamine influences sarcoplasmic proteome profile of pork Longissimus thoracis. Meat Sci. 103, 7-12.

Faustman, C., Cassens, R., Schaefer, D., Buege, D., Williams, S. \& Scheller, K., 1989. Improvement of pigment and lipid stability in Holstein steer beef by dietary supplementation with vitamin E. J. Food Sci. 54, 858-862.

Faustman, C., Chan, W.K., Schaefer, D.M. \& Havens, A., 1998. Beef colour update: The role for vitamin E. J. Anim. Sci. 76, 1019-1026.

Faustman, C., Sun, Q., Mancini, R. \& Suman, S.P., 2010. Myoglobin and lipid oxidation interactions: Mechanistic bases and control. Meat Sci. 86, 86-94.

Gutierrez, A.M., Reboredo, G.R. \& Catala, A., 2002. Fatty acid profiles and lipid peroxidation of microsomes and mitochondria from liver, heart and brain of Cairina moschata. Int. J. Biochem. Cell Biol. 34, 605-612.

Harsh, B.N., Dilger, A.C., Boler, D.D. \& Shike, D.W., 2018. Effects of a multielement trace mineral injection and vitamin E supplementation on performance, carcass characteristics, and colour stability of strip steaks from feedlot heifers. J. Anim. Sci. 96, 1745-1756.

Joseph, P., Suman, S.P., Rentfrow, G., Li, S. \& Beach, C.M., 2012. Proteomics of muscle-specific beef colour stability. J. Agric. Food Chem. 60, 3196-3203.

Ke, Y., Mitacek, R.M., Abraham, A., Mafi, G.G., VanOverbeke, D.L., DeSilva, U. \& Ramanathan, R., 2017. Effects of Muscle-Specific oxidative stress on cytochrome c release and oxidation-reduction potential properties. J. Agric. Food Chem. 65, 7749-7755.

Lambeth, D.O., Tews, K.N., Adkins, S., Frohlich, D. \& Milavetz, B.I., 2004. Expression of two succinyl-CoA synthetases with different nucleotide specificities in mammalian tissues. J. Biol. Chem. 279, 36621-36624.

Lanari, M. \& Cassens, R., 1991. Mitochondrial activity and beef muscle colour stability. J. Food Sci. 56, $1476-1479$.

Lass, A. \& Sohal, R.S., 1998. Electron transport-linked ubiquinone-dependent recycling of a-tocopherol inhibits autooxidation of mitochondrial membranes. Arch. Biochem. Biophys. 352, 229-236.

Liu, Q., Lanari, M.C. \& Schaefer, D.M., 1995. A review of dietary vitamin E supplementation for improvement of beef quality. J. Anim. Sci. 73, 3131-3140.

Mancini, R.A. \& Hunt, M.C., 2005. Current research in meat colour. Meat Sci. 71, 100-121.

Mancini, R.A. \& Ramanathan, R., 2014. Effects of postmortem storage time on colour and mitochondria in beef. Meat Sci. 98, 65-70.

Meunier, B., Bouley, J., Piec, I., Bernard, C., Picard, B. \& Hocquette, J.F., 2005. Data analysis methods for detection of differential protein expression in two-dimensional gel electrophoresis. Anal. Biochem. 340, 226-230.

Mohan, A., Hunt, M.C., Muthukrishnan, S., Barstow, T.J. \& Houser, T.A., 2010. Myoglobin redox form stabilization by compartmentalized lactate and malate dehydrogenases. J. Agric. Food Chem. 58, 7021-7029.

Muller, F.L., Liu, Y., Abdul-Ghani, M.A., Lustgarten, M.S., Bhattacharya, A., Jang, Y.C. \& Van Remmen, H., 2008. High rates of superoxide production in skeletal-muscle mitochondria respiring on both complex I- and complex II-linked substrates. Biochem. J. 409, 491-499.

Murphy, M.P., 2009. How mitochondria produce reactive oxygen species. Biochem. J. 417, 1-13.

Nair, M.N., Suman, S.P., Chatli, M.K., Li, S., Joseph, P., Beach, C.M. \& Rentfrow, G., 2016. Proteome basis for intramuscular variation in colour stability of beef semimembranosus. Meat Sci. 113, 9-16.

Neethling, N.E., Suman, S.P., Sigge, G.O., Hoffman, L.C. \& Hunt, M.C., 2017. Exogenous and endogenous factors influencing colour of fresh meat from ungulates. Meat Mus. Bio. 1, 253-275.

Raha, S. \& Robinson, B.H., 2000. Mitochondria, oxygen free radicals, disease and ageing. Trends Biochem. Sci. 25, 502-508.

Ramanathan, R. \& Mancini, R.A., 2010. Effects of pyruvate on bovine heart mitochondria-mediated metmyoglobin reduction. Meat Sci. 86, 738-741.

Ramanathan, R. \& Mancini, R. A., 2018. Role of mitochondria in beef colour: A review. Meat Mus. Bio. In Press. DOI: 10.22175/mmb2018.05.0013

Ramanathan, R., Mancini, R.A. \& Maheswarappa, N.B., 2010. Effects of lactate on bovine heart mitochondria-mediated metmyoglobin reduction. J. Agric. Food Chem. 58, 5724-5729.

Sales, J. \& Koukolova, V., 2011. Dietary vitamin E and lipid and colour stability of beef and pork: Modeling of relationships. J. Anim. Sci. 89, 2836-2848.

Strobel, N.A., Peake, J.M., Matsumoto, A., Marsh, S.A., Coombes, J.S. \& Wadley, G.D., 2011. Antioxidant supplementation reduces skeletal muscle mitochondrial biogenesis. Med. Sci. Sports Exerc. 43, 1017-1024.

Suman, S.P., Faustman, C., Stamer, S.L. \& Liebler, D.C., 2007. Proteomics of lipid oxidation-induced oxidation of porcine and bovine oxymyoglobins. Proteomics. 7, 628-640.

Suman, S.P. \& Joseph, P., 2013. Myoglobin chemistry and meat colour. Annu Rev. Food Sci. 4, 79-99.

Suman, S.P., Hunt, M.C., Nair, M.N. \& Rentfrow, G., 2014. Improving beef colour stability: Practical strategies and underlying mechanisms. Meat Sci. 98, 490-504.

Tang, J., Faustman, C., Mancini, R.A., Seyfert, M. \& Hunt, M.C., 2005a. Mitochondrial reduction of metmyoglobin: Dependence on the electron transport chain. J. Agric. Food Chem. 53, 5449-5455.

Tang, J., Faustman, C., Hoagland, T.A., Mancini, R.A., Seyfert, M. \& Hunt, M.C., 2005b. Interactions between mitochondrial lipid oxidation and oxymyoglobin oxidation and the effects of vitamin E. J. Agric. Food Chem. 53, 6073-6079. 
Traber, M.G. \& Stevens, J.F., 2011. Vitamins C and E: Beneficial effects from a mechanistic perspective. Free Radic. Biol. Med. 51, 1000-1013.

Tretter, L. \& Adam-Vizi, V., 2005. Alpha-ketoglutarate dehydrogenase: A target and generator of oxidative stress. Philos. Trans. R. Soc. Lond. B. Biol. Sci. 360, 2335-2345.

Turrens, J.F., 2003. Mitochondrial formation of reactive oxygen species. J. Physiol. 552, 335-344.

Wittenberg, J.B. \& Wittenberg, B.A., 2007. Myoglobin-enhanced oxygen delivery to isolated cardiac mitochondria. J. Exp. Biol. 210, 2082-2090.

Wu, J., Nair, M., Suman, S., Li, S., Luo, X., Beach, C., Bohrer, B. \& Boler, D., 2017. Ractopamine-induced changes in sarcoplasmic proteome profile of post-rigor pork semimembranosus muscle. S. Afr. J. Anim. Sci. 47, 640-647. 